\title{
Atropine and ODQ antagonize tetanic fade induced by L-arginine in cats
}

J.M. Cruciol-Souza ${ }^{1}$ and W. Alves-Do-Prado²

\section{Correspondence \\ W. Alves-Do-Prado \\ Departamento de Farmácia e \\ Farmacologia \\ Universidade Estadual de Maringá \\ Av. Colombo, 3690 \\ Bloco K-80, Sala 6 \\ 87020-900 Maringá, PR \\ Brasil \\ Fax: + 55-44-225-3863 \\ E-mail: alvesprado@wnet.com.br}

Research supported by CN Pq.

Received October 9, 1998

Accepted July 12, 1999

\author{
${ }^{1}$ Departamento de Ciências Fisiológicas, \\ Universidade Estadual de Londrina, Londrina, PR, Brasil \\ 2Departamento de Farmácia e Farmacologia, \\ Universidade Estadual de M aringá, M aringá, PR, Brasil
}

\section{Abstract}

Although it has been demonstrated that nitric oxide (NO) released from sodium nitrite induces tetanic fade in the cat neuromuscular preparations, the effect of L-arginine on tetanic fade and its origin induced by NO have not been studied in these preparations. Furthermore, atropine reduces tetanic fade induced by several cholinergic and anticholinergic drugs in these preparations, whose mechanism is suggested to be mediated by the interaction of acetylcholine with inhibitory presynaptic muscarinic receptors. The present study was conducted in cats to determine the effects of L-arginine alone or after pretreatment with atropine or $1 \mathrm{H}-[1,2,4]$ oxadiazole [4,3-a]quinoxalin1-one (ODQ) on neuromuscular preparations indirectly stimulated at high frequency. Drugs were injected into the middle genicular artery. L-arginine $(2 \mathrm{mg} / \mathrm{kg}$ ) and S-nitroso-N-acetylpenicillamine (SNAP; 16 $\mu \mathrm{g} / \mathrm{kg}$ ) induced tetanic fade. The $\mathrm{N}^{\omega}$-nitro-L-arginine (L-NOARG; 2 $\mathrm{mg} / \mathrm{kg}$ ) alone did not produce any effect, but reduced the tetanic fade induced by L-arginine. D-arginine $(2 \mathrm{mg} / \mathrm{kg})$ did not induce changes in tetanic fade. The tetanic fade induced by L-arginine or SNAP was reduced by previous injection of atropine $(1.0 \mu \mathrm{g} / \mathrm{kg})$ or ODQ $(15 \mu \mathrm{g} /$ $\mathrm{kg}$ ). ODQ alone did not change tetanic fade. The data suggest that the NO-synthase-GC pathway participates in the L-arginine-induced tetanic fade in cat neuromuscular preparations. The tetanic fade induced by L-arginine probably depends on the action of $\mathrm{NO}$ at the presynaptic level. NO may stimulate guanylate cyclase increasing acetylcholine release and thereby stimulating presynaptic muscarinic receptors.

\section{Introduction}

Endogenous nitric oxide (NO) is formed from L-arginine through the NO-synthase pathway (1). This pathway is present in the sarcolemma of type II fibers of rat skeletal muscle in which contractility is depressed by NO donors or by 8-bromo-cGMP when the preparations are directly stimulated (2). In contrast, NO increases the amplitude of mus-
Key words

- Atropine

- Tetanic fade

- Skeletal muscle

- Nitric oxide

- Muscarinic receptors cular contraction of the phrenic-nerve diaphragm preparation indirectly stimulated at low frequency, but reduces contractility when curarized preparations are directly stimulated (3). Therefore, it is proposed that NO increases the amplitude of muscular contraction when it interacts at the presynaptic level, but decreases the amplitude of twitches when it acts at the postsynaptic level (3). The presynaptic action of NO reduces the effect 
produced by its postsynaptic action (3).

In myographic records, tetanic fade, also known as Wedensky inhibition, is a poorly sustained contraction that follows a fast muscular contraction of high amplitude when the motor nerve is receiving high frequencies of electrical stimulation (Figure 1). Skeletal muscles respond with sustained contractions when the nerve is stimulated at physiological frequencies $(30-80 \mathrm{~Hz})$, however, Wedensky inhibition may be achieved when frequencies of stimulation higher than 100 $\mathrm{Hz}$ are applied to the motor nerve $(4,5)$. However, tetanic fade may follow nerve stimulation even at lower frequencies if muscle is treated with d-tubocurarine, hexamethonium or an anticholinesterase agent (6). It has been proposed that acetylcholine, in addition to acting on subsynaptic membranes, also acts on prejunctional cholinoceptors to change the acetylcholine mobilization process and thus to control the neurotransmitter output during tetanic stimulation (5). Nicotinic (7) and muscarinic presynaptic receptors $(8,9)$ exist on motor nerves. The blockade of nicotinic presynaptic receptors by curare-like drugs decreases (10), whereas blockade of muscarinic presynaptic receptors by atropine increases acetylcholine output from neuromuscular preparations (11). The tetanic fades induced by d-tubocurarine, hexamethonium or neostigmine are reduced by previous treatment of neuromuscular preparations with atropine $(0.25-1.0 \mu \mathrm{g} / \mathrm{kg})$ (5). Therefore, it is accepted that tetanic fade induced by these drugs is affected by acetyl-

Figure 1 - Diagrammatic representation of the contractile responses of cat anterior tibial muscle during tetanic stimulation. Tetanic fade is calculated as the ratio $(R)$ between the tension at the end $(B)$ and the tension at the beginning (A) of the tetanic response ( $R$ $=\mathrm{B} / \mathrm{A})$. $\mathrm{C}$ and $\mathrm{D}$ correspond to pre-tetanic and post-tetanic twiches, respectively. F represents the stimulation rate required to obtain $R=0.5$. release from central and peripheral cholinergic neurons and decrease the action potential-evoked acetylcholine release from enteric neurons (12). Thus, it has been suggested that NO may be important in the control of acetylcholine release from enteric tissues (12). On the other hand, it has been shown that NO released from sodium nitrite induces a dose-dependent increase in Wedensky inhibition when high frequencies are applied to the nerves of neuromuscular preparations from cats (13). Furthermore, the origin of the tetanic fade induced by NO and the effects of L-arginine on tetanic fade have not been studied in these preparations. Since it is known that atropine may reduce the tetanic fade induced by drugs that interfere with the modulation of acetylcholine release from motor nerve terminals (5), the present work was carried out to determine the effects of atropine and $1 \mathrm{H}-[1,2,4]$ oxadiazole [4,3-a]quinoxalin-1-one (ODQ) on tetanic fade induced by $\mathrm{NO}$ of endogenous or exogenous (S-nitroso-N-acetylpenicillamine; SNAP) origin in neuromuscular preparation of cats.

\section{Material and Methods}

Cats of either sex weighing 2-3.5 kg were used in this study. Each animal was anesthetized with a combination of $\alpha$-chloralose, 60 $\mathrm{mg} / \mathrm{kg} i v$, and urethane, $600 \mathrm{mg} / \mathrm{kg} i v$. The anterior tibial muscle was prepared for the recording of isometric twitch tension by means of a previously described method (5). The hind limb was fixed to a Brown-Schustertype myograph by means of a metal pin screwed through the head of the tibia. The distal tendon was dissected free and tied to a force-displacement transducer coupled to a Ugo Basile polygraph (Varese, Italy). The popliteal artery was exposed and all branches except those of the anterior tibial muscle and of the middle genicular artery were tied off. For intra-arterial drug injection, a polyethylene cannula was introduced into the middle 
genicular artery and tied close to the popliteal artery. During intra-arterial injection of the drugs, the anterior tibial artery was occluded just below the entrance of its branch into the anterior tibial muscle. Contractions of tibial muscle were caused by electrical stimulation of the sciatic nerve with supramaximal square wave pulses of 0.05 -ms duration. In all experiments the standard rate of stimulation was $0.2 \mathrm{~Hz}$, but stimulation at a higher (tetanic) rate was applied to the nerve for $10 \mathrm{~s}$ at 10-min intervals. The tension produced at the beginning of tetanic stimulation (A) was compared to that obtained at the end of tetanic stimulation (B) (Figure 1). The stimulation rate $(F)$ required to obtain a 0.5 ratio $(\mathrm{R}=\mathrm{B} / \mathrm{A})$ was determined for each preparation and $F / 2$ was then used throughout the experiment. Saline $(0.05 \mathrm{ml})$ was injected into the artery (time $(\mathrm{t})=0$ ) and $\mathrm{F} / 2$ was applied to the nerve $5 \mathrm{~min}$ later. L-Arginine, $\mathrm{D}$-arginine or SNAP were administrated at $\mathrm{t}$ $=10 \mathrm{~min}$. The lowest dose of L-arginine or SNAP that reduced $\mathrm{R}$ values to about $12-$ $14 \%$ of the $\mathrm{R}$ control was determined and tetanic stimulation was then repeated at $\mathrm{t}=$ $15,25,35$ and $45 \mathrm{~min}$. The lowest doses of atropine and ODQ able to reduce the tetanic fade induced by L-arginine were determined and used in the experiments with SNAP. The lowest dose of $\mathrm{N}^{\omega}$-nitro-L-arginine (LNOARG) that antagonized the effects of the amino acids was also determined and the same experimental sequence was repeated 60 min later with saline containing atropine, ODQ or L-NOARG injected at $\mathrm{t}=0 \mathrm{~min}$. The anterior tibial artery was freed at $\mathrm{t}=16 \mathrm{~min}$. Variations in $\mathrm{R}$ were analyzed as percent $\mathrm{R}$ obtained in the absence of drugs and were named percentage of tetanic fade. Percentage of tetanic fade was plotted against the time after drug administration. All drugs were dissolved in saline and doses were applied in a maximum volume of $0.1 \mathrm{ml}$ and injected as a bolus followed by washing of the cannula with drug-free saline $(0.1 \mathrm{ml})$. All exposed tissues in the preparation were covered with mineral oil. Data obtained in the absence (control) or presence of L-arginine, D-arginine or SNAP were analyzed by the Student $t$-test for paired data, with the level of significance set at $\mathrm{P}<0.05$.

\section{Drugs}

The following drugs were used: $\alpha$-chloralose, L-arginine and D-arginine hydrochloride, urethane ethyl carbamate, L-NOARG, and atropine sulfate from Sigma (St. Louis, MO, USA), and SNAP and ODQ from Research Biochemical Incorporated (RBI; Natick, MA, USA).

\section{Results}

L-Arginine $(2 \mathrm{mg} / \mathrm{kg})$ or SNAP $(16 \mu \mathrm{g} /$ $\mathrm{kg}$ ) produced tetanic fade with a maximal effect observed at $\mathrm{t}=15 \mathrm{~min}$ (Figures 2, 4). L-NOARG $(2 \mathrm{mg} / \mathrm{kg})$ alone did not produce Wedensky inhibition, but reduced the te-

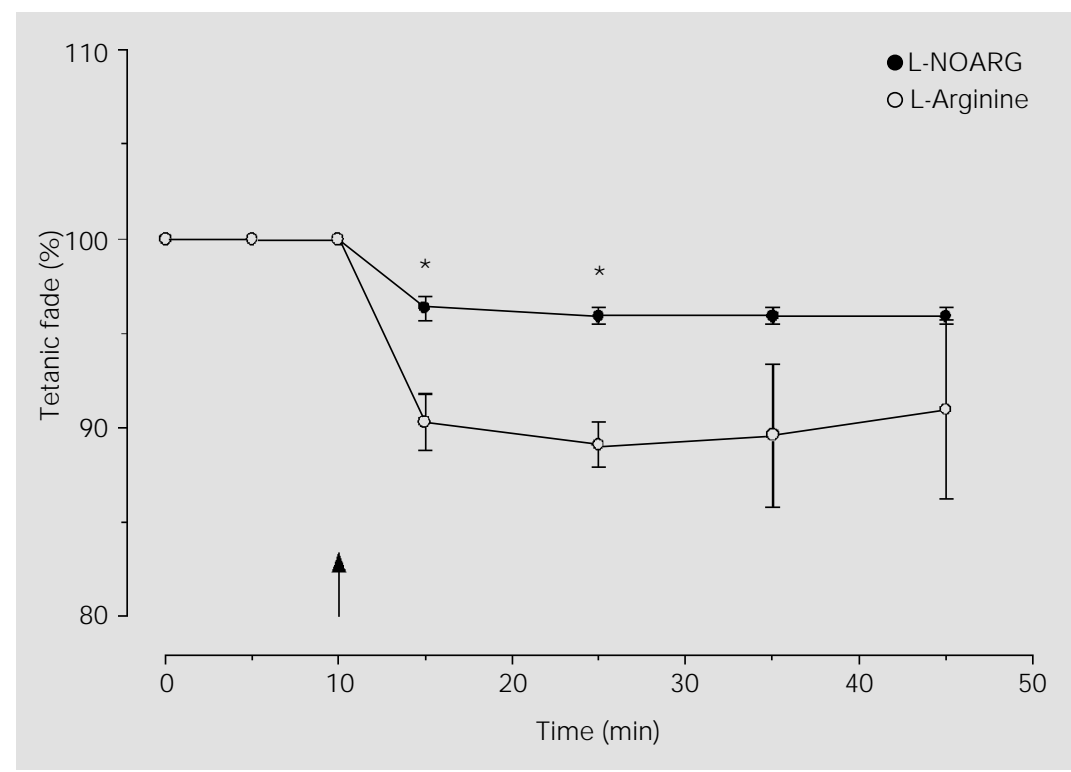

Figure 2 - Antagonism by L-NOARG ( $2 \mathrm{mg} / \mathrm{kg}$ ) (filled circles) of tetanic fade induced by Larginine ( $2 \mathrm{mg} / \mathrm{kg}$ ) (open circles) in cat anterior tibial muscle preparations. L-Arginine was injected at time $t=10 \mathrm{~min}$ (arrow). The drugs were administered through the middle genicular artery. Points indicate mean \pm SEM of 5 experiments. On the ordinate, tetanic fade expressed as percentage of that obtained $5 \mathrm{~min}$ after injection of drug-free saline, taken as $100 \%$. $* \mathrm{P}<0.05$ compared to the results observed with L-arginine alone (Student ttest for paired data). 


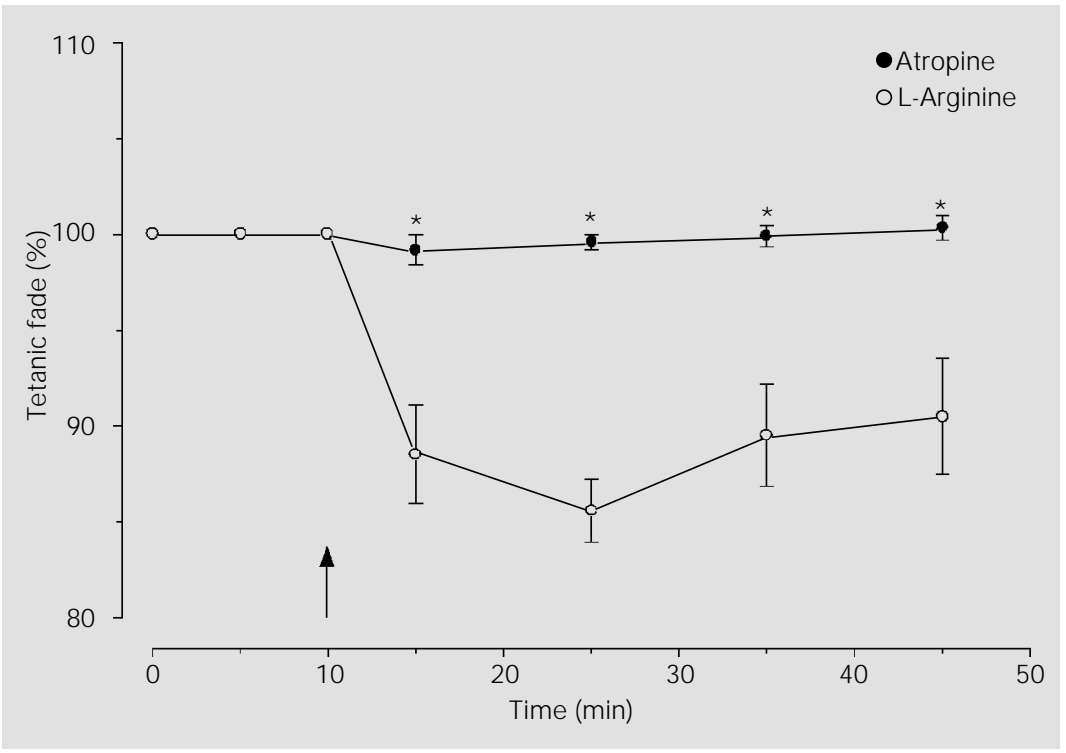

Figure 3 - Antagonism by atropine $(1.0 \mu \mathrm{g} / \mathrm{kg}$ ) (filled circles) of tetanic fade induced by Larginine ( $2 \mathrm{mg} / \mathrm{kg}$ ) (open circles) in cat anterior tibial muscle preparations. L-Arginine was injected at time $\mathrm{t}=10 \mathrm{~min}$ (arrow). The drugs were administered through the middle genicular artery. Points indicate the mean \pm SEM of 5 experiments. On the ordinate, \% tetanic fade as shown in Figure 2. $* \mathrm{P}<0.05$ compared to the results observed with Larginine alone (Student t-test for paired data).

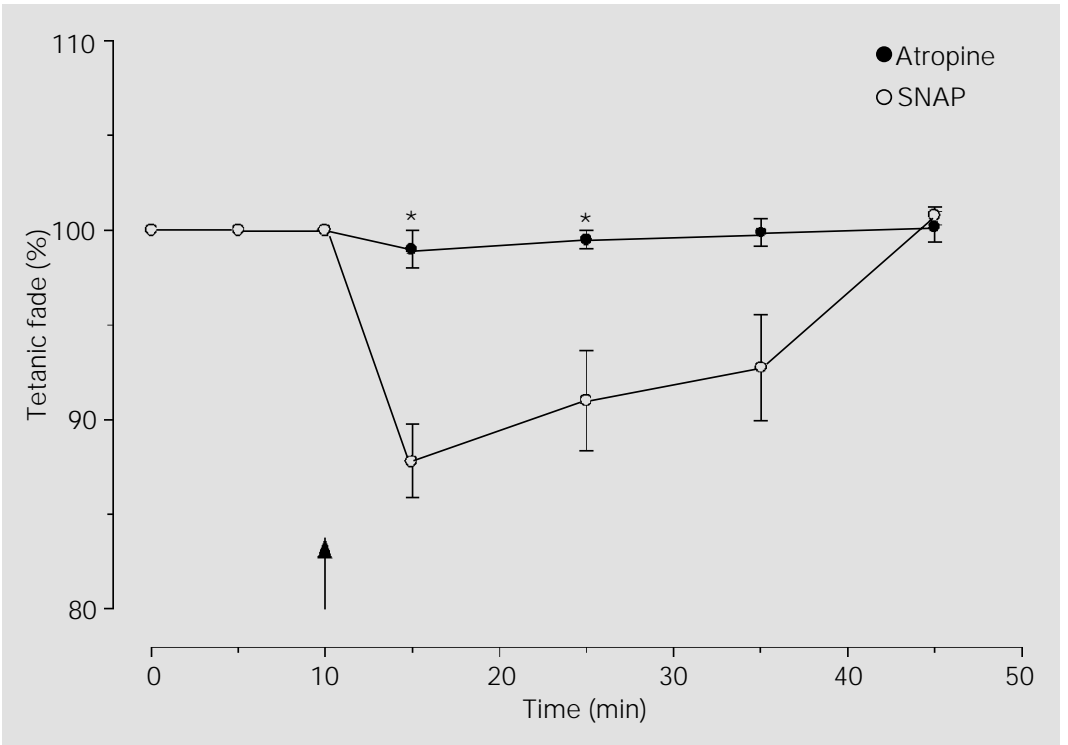

Figure 4 - Antagonism by atropine $(1.0 \mu \mathrm{g} / \mathrm{kg}$ ) (filled circles) of tetanic fade induced by SNAP $(16 \mu \mathrm{g} / \mathrm{kg})$ (open circles) in cat anterior tibial muscle preparations. SNAP was injected at time $\mathrm{t}=10 \mathrm{~min}$ (arrow). The drugs were administered through the middle genicular artery. Points indicate the mean \pm SEM of 4 experiments. On the ordinate, \% tetanic fade as shown in Figure 2. $* \mathrm{P}<0.05$ compared to the results observed with SNAP alone (Student t-test for paired data). tanic fade induced by L-arginine $(2 \mathrm{mg} / \mathrm{kg})$ (Figure 2). D-arginine $(2 \mathrm{mg} / \mathrm{kg})$ did not induce any changes in $\mathrm{R}$ values (data not shown). The tetanic fade induced by SNAP $(16 \mu \mathrm{g} / \mathrm{kg})$ or L-arginine $(2 \mathrm{mg} / \mathrm{kg})$ was reduced by previous treatment of the preparation with atropine $(1.0 \mu \mathrm{g} / \mathrm{kg})$ (Figures 3, 4) or ODQ $(15 \mu \mathrm{g} / \mathrm{kg})$, which alone did not produce any change in $\mathrm{R}$ values (Figures 5, $6)$.

\section{Discussion}

Intra-arterial injection of L-arginine or SNAP induced Wedensky inhibition when high frequencies of stimulation were applied to the nerve of a cat neuromuscular preparation. The possibility that the tetanic fade induced by both drugs arises from an anticholinesterase mode of action seems unlikely because a previous study has shown that the neuromuscular effects produced by those agents were not mediated by cholinesterase inhibition (3).

L-NOARG did not produce any change in $\mathrm{R}$ values, but antagonized the tetanic fade induced by L-arginine when high frequency was applied to the nerve. The effect of Larginine was stereospecific since D-arginine $(2 \mathrm{mg} / \mathrm{kg})$ was not effective in similar experiments. Since L-NOARG and L-arginine are taken up by the cell through different carrier systems (14), the results observed with administration of L-arginine indicate the participation of the NO synthase pathway in the tetanic fade induced by the amino acid. The results obtained with SNAP confirmed a previous report with NO obtained from sodium nitrite in similar studies (13) and support the possibility that tetanic fade induced by L-arginine may be mediated by an NO action, probably at the presynaptic level.

The NO-synthase pathway is present in skeletal muscle (2), motor nerve terminal (15) and vascular smooth muscle (1). Therefore, the effects observed with L-arginine might be mediated by NO produced by 
different tissues.

Previous activation of $\mathrm{M}_{3}$ muscarinic receptors induces the synthesis of NO from Larginine in vascular smooth muscle (1). Thus, the antagonism observed with atropine of tetanic fade induced by L-arginine might be explained by a reduction in NO synthase activity in vascular smooth muscle. The same mechanism could not explain the antagonism by atropine of tetanic fade induced by SNAP because the literature does not give evidence that the NO released from SNAP depends on NO-synthase activity or on a direct interaction with muscarinic receptors. The tetanic fade induced by endogenous or exogenous NO might depend on block of nicotinic receptors, on plug of ionic channels or on an action inside the muscle. Such possibilities seem unlikely since previous studies have shown that atropine plugs nicotinic channel and blocks part of nicotinic receptors (16), but does not produce tetanic fade (5). Furthermore, it has been shown that the antagonism by atropine of tetanic fade induced by different agents may originate at the level of presynaptic muscarinic receptors (5). Thus, the antagonisms observed with atropine might indicate that the tetanic fade induced by NO would be produced by an indirect action of the gas on motor nerves, increasing acetylcholine output and stimulating inhibitory presynaptic muscarinic receptors. Indeed, it has been shown that endogenous and exogenous NO increases basal acetylcholine release from central and peripheral cholinergic neurons (12).

The lowest dose of L-arginine $(2.0 \mathrm{mg} /$ $\mathrm{kg}$ ) that induced Wedensky inhibition was higher than that found for SNAP $(16 \mu \mathrm{g} / \mathrm{kg})$. This difference might depend on the metabolism of L-arginine by NO-synthase producing progressive NO formation. It might also depend on the scavenger action of hemoglobin (17). The possibility that it might depend on different affinity of the agents for the same receptor seems unlikely because the effects induced by L-arginine and SNAP

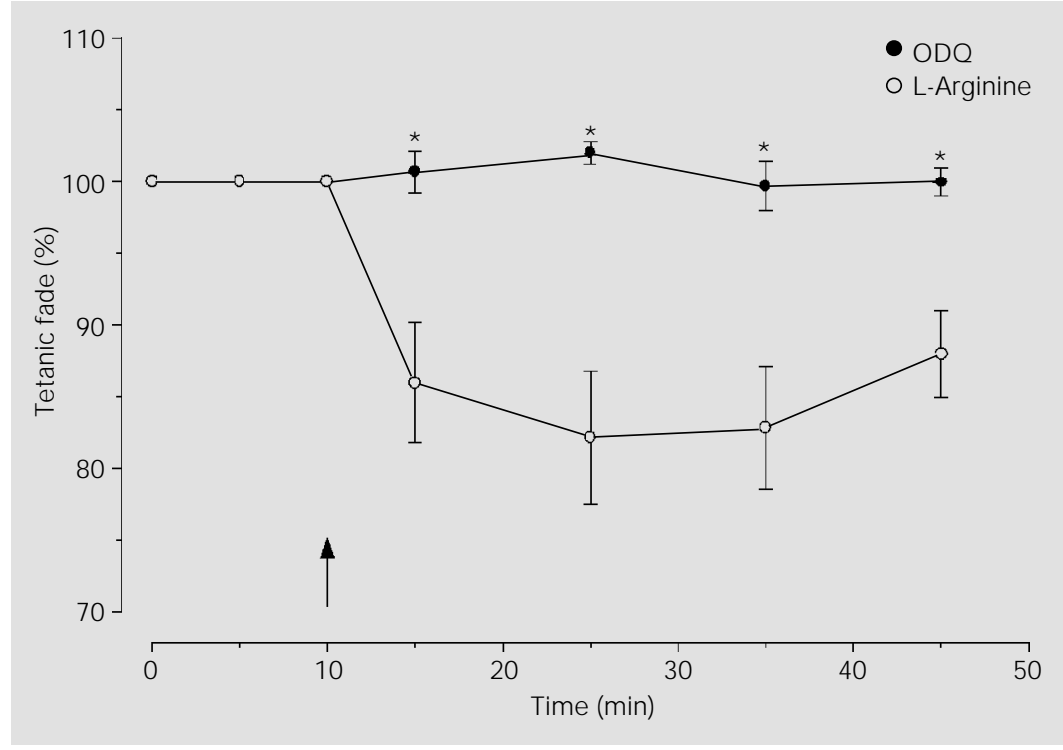

Figure 5 - Antagonism by ODQ ( $15 \mu \mathrm{g} / \mathrm{kg}$ ) (filled circles) of tetanic fade induced by L-arginine ( $2 \mathrm{mg} / \mathrm{kg}$ ) (open circles) in cat anterior tibial muscle preparations. L-Arginine was injected at time $\mathrm{t}=10 \mathrm{~min}$ (arrow). Drugs were administered through the middle genicular artery. Points indicate the mean \pm SEM of 5 experiments. On the ordinate, $\%$ tetanic fade as shown in Figure 2. $* \mathrm{P}<0.05$ compared to the results observed with L-arginine alone (Student t-test for paired data).

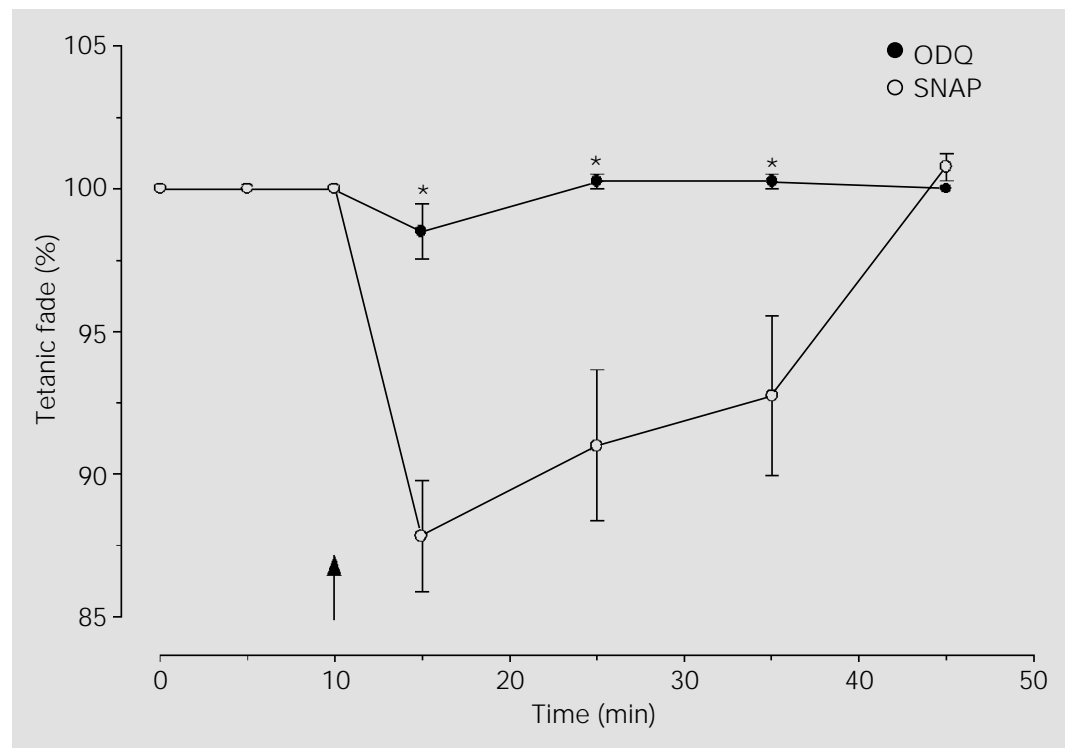

Figure 6 - Antagonism by ODQ (15 $\mu \mathrm{g} / \mathrm{kg}$ ) (filled circles) of tetanic fade induced by SNAP (16 $\mu \mathrm{g} / \mathrm{kg}$ ) (open circles) in cat anterior tibial muscle preparations. SNAP was injected at time $t=$ 10 min (arrow). The drugs were administered through the middle genicular artery. Points indicate the mean \pm SEM of 5 experiments. On the ordinate, $\%$ tetanic fade as shown in Figure 2. $* \mathrm{P}<0.05$ compared to the results observed with SNAP (Student $\mathrm{t}$-test for paired data). 
are not produced by direct interaction with nicotinic or muscarinic receptors $(18,19)$. Neither L-NOARG nor ODQ alone produced any change in $R$ values when a high frequency was applied to the motor nerve. This observation probably was determined by a low concentration of L-arginine available in tissues, which did not produce enough NO to stimulate guanylate cyclase (20).

The Wedesnky inhibition induced by SNAP and L-arginine was antagonized by previous administration of ODQ, a guanylate cyclase blocker (21). The antagonism observed between SNAP and ODQ confirms previous results that methylene blue reverses the sodium nitrite-induced tetanic fade in cats (13). This fact suggests that the effects observed in the present study may depend on an interaction of NO and guanylate cyclase. Therefore, it is possible to suggest that NOinduced Wedensky inhibition may be medi- ated by an increase in guanylate cyclase activity which produces an increase in acetylcholine release from nerve endings. This hypothesis is favored by the observation that 8-Br-cGMP increases the release of acetylcholine from the guinea pig myenteric plexus (12).

Taken as a whole, our results suggest that the NO-synthase pathway participates in the L-arginine-induced tetanic fade in neuromuscular preparations of cats. The tetanic fade induced by L-arginine may depend on $\mathrm{NO}$ action on guanylate cyclase; it increases acetylcholine release from motor nerve terminals, with a consequent activation of presynaptic muscarinic receptors.

\section{Acknowledgments}

We are grateful to Mrs. Irani Lopes dos Santos for technical support.

\section{References}

1. Moncada S, Palmer RMJ \& Higgs A (1991). Nitric oxide: physiology, pathophysiology and pharmacology. Pharmacological Reviews, 43: 109-142.

2. Kobzik L, Reed MB, Bredt DS \& Stamler J S (1994). Nitric oxide in skeletal muscle. Nature, 372: 546-548.

3. Ambiel CR \& Alves-Do-Prado W (1997). Neuromuscular facilitation and blockade induced by L-arginine and nitric oxide in the rat isolated diaphragm. General Pharmacology, 28: 789-794.

4. Bowman WC (1980). Prejunctional and postjunctional cholinoceptors at the neuromuscular junction. Anesthesia and Analgesia, 59: 935-943.

5. Alves-Do-Prado W, Corrado AP \& Prado WA (1987). Reversal by atropine of tetanic fade induced in cats by antinicotinic and anticholinesterase agents. Anesthesia and Analgesia, 66: 492-496.

6. Bowman WC \& Webb SN (1972). Acetylcholine and anticholinesterase drugs. In: Cheymol J (Editor), Neuromuscular Blocking and Stimulating Agents. Pergamon Press, Oxford, 427-432. (Radouco-Thomas C (Editor), International Encyclopedia of Pharmacology and Therapeutics, Sec- tion 14, Vol. 2)

7. Miyamoto MD (1978). The actions of cholinergic drugs on motor nerve terminals. Pharmacological Reviews, 29: 221-247.

8. Duncan CJ \& Publicover SJ (1979). Inhibitory effects of cholinergic agents on the release of transmitter at the frog neuromuscular junction. J ournal of Physiology, 294: 91-103.

9. Michaelson DM, Avissar S, Kloog $Y \&$ Sokolowsky M (1979). Mechanism of acetylcholine release: possible involvement of presynaptic muscarinic receptors in regulation of acetylcholine release and protein phosphorylation. Proceedings of the National Academy of Sciences, USA, 76: 6336-6340

10. Galindo A (1972). The role of prejunctional effects in myoneural transmission. Anesthesiology, 36: 598-608.

11. Abbs ET \& J oseph DN (1981). The effects of atropine and oxotremorin on acetylcholine release in rat phrenic nerve-diaphragm preparations. British J ournal of Pharmacology, 73: 481-483.

12. Kilbinger H (1996). Modulation of acetylcholine release by nitric oxide. Progress in Brain Research, 109: 219-224.
13. Ambiel CR \& Alves-Do-Prado W (1998) Reversal by methylene blue of tetanic fade induced in cats by nitric oxide. Brazilian J ournal of Medical and Biological Research, 31: 413-415.

14. Rao VL \& Butterworth RF (1996). L-[3H] nitroarginine and $\mathrm{L}-[3 \mathrm{H}]$ arginine uptake into rat cerebellar synaptosomes: kinetics and pharmacology. J ournal of Neurochemistry, 67: 1275-1281.

15. Ribeira J, Marsal J, Casanova A, Hukkanen M, Tarabal O \& Esquerda J E (1998). Nitric oxide synthase in rat neuromuscular junctions and in nerve terminals of Torpedo electric organ: its role as regulator of acetylcholine release. Journal of Neuroscience Research, 51: 90-102.

16. Zwart R \& Vijverberg HP (1997). Potentiation and inhibition of neuronal nicotinic receptors by atropine: competitive and non-competitive effects. Molecular Pharmacology, 52: 886-895.

17. Gibson A \& Lilley E (1997). Superoxide anions, free-radical scavengers, and nitrergic neurotransmission. General Pharmacology, 28: 489-493.

18. Scheller $M$, Blobner $M$, Loewenich $C$, Schneck H, Stadler J , Franke C \& Kochs E 
(1998). The NO synthase inhibitors LNAME and L-NMMA, but not L-arginine, block the mammalian nicotinic acetylcholine receptor channel. Toxicology Letters, 23: 109-113.

19. Buxton ILO, Cheek DJ, Eckman D, Westfall DP, Sanders KM \& Keef KD
(1993). $\mathrm{N}^{\mathrm{G}}$-Nitro L-arginine methyl ester and other alkyl esters of arginine are muscarinic receptor antagonists. Circulation Research, 72: 387-395.

20. Moncada S, Palmer RMJ \& Higgs A (1989). Biosynthesis of nitric oxide from L-arginine. A pathway for the regulation of cell function and communication. Biochemical Pharmacology, 38: 1709-1715.

21. Boulton CL, Southam E \& Gartwaite J (1995). Nitric oxide-dependent long-term potentiation is blocked by a specific inhibitor of soluble guanylyl cyclase. Neuroscience, 69: 699-703. 